\title{
The Chinese herb Prunella vulgaris promotes apoptosis in human well-differentiated thyroid carcinoma cells via the B-cell lymphoma-2/Bcl-2-associated $X$ protein/caspase-3 signaling pathway
}

\author{
DE-TAO YIN ${ }^{1,2}$, MENGYUAN LEI ${ }^{1,2}$, JIANHUI XU ${ }^{1,2}$, HONGQIANG LI $^{1,2}$, YONGFEI WANG $^{1,2}$, \\ ZHEN LIU ${ }^{1,2}$, RUNSHENG MA ${ }^{1,2}, \mathrm{KUN} \mathrm{YU}^{1,2}$ and XIANGHUA LI ${ }^{1,2}$ \\ ${ }^{1}$ Department of Thyroid Surgery, The First Affiliated Hospital of Zhengzhou University, Zhengzhou, \\ Henan 450052; ${ }^{2}$ Key Discipline Laboratory of Clinical Medicine Henan, Zhengzhou, Henan 450050, P.R. China
}

Received February 13, 2016; Accepted February 7, 2017

DOI: $10.3892 / \mathrm{ol} .2017 .6317$

\begin{abstract}
Prunella vulgaris (PV), a traditional Chinese herb, has been shown to be rich in bioactive chemicals and possess anti-proliferative and pro-apoptotic effects on tumor cells. The effect of PV on human well-differentiated thyroid carcinoma (WDTC), which accounts for the majority of common endocrine malignancies, remains to be elucidated. The present study aimed to investigate the function of PV on WDTC cell lines and apoptosis-associated signaling pathway activity. Additional studies demonstrated that PV may induce apoptosis in WDTC TPC-1 and FTC-133 cell lines, using the Cell Counting Kit-8 assay. Morphological changes of apoptotic cells were observed by Hoechst 33342 and acridine orange/ethidium bromide staining. In addition, ladder pattern of fragmented DNA was observed by DNA gel electrophoresis. It was also observed that PV significantly increased Bcl-2-associated $\mathrm{X}$ protein and caspase-3 expression, and downregulated B-cell lymphoma-2 expression in TPC-1 and FTC-133 by reverse transcription-quantitative polymerase chain reaction $(\mathrm{P}<0.05)$. Thus, the present results indicated that PV has the potential to be a future WDTC therapeutic agent.
\end{abstract}

\section{Introduction}

Thyroid carcinoma is the most common endocrine malignancy, comprising $90 \%$ of endocrine cancers, but representing

Correspondence to: Dr De-Tao Yin, Department of Thyroid Surgery, The First Affiliated Hospital of Zhengzhou University, 1 Jianshe Road, Zhengzhou, Henan 450052, P.R. China

E-mail: detaoyin@zzu.edu.cn

Key words: Prunella vulgaris, well-differentiated thyroid carcinoma, apoptosis, anti-proliferative, B-cell lymphoma-2, Bcl-2-associated X protein, caspase- 3 $\sim 1 \%$ of whole-body malignant cancers $(1,2)$. Thyroid cancer is classified into three types: Well-differentiated; poorly-differentiated; and undifferentiated (3). The most prevalent types of thyroid cancer are well-differentiated [papillary thyroid cancer (PTC) and follicular thyroid cancer (FTC)] thyroid carcinomas, which make up $\sim 93 \%$ of all thyroid cancers $(4,5)$. In addition, the incidence of well-differentiated thyroid cancers (WDTC) has increased dramatically in the past decade (6). Currently, surgical resection remains the most effective treatment for this cancer. Therefore, finding an effective natural medicine that has anti-WDTC effects is may be of great importance.

There is increasing interest in herbal and botanical remedies in oncotherapy. The botanical herb Prunella vulgaris (PV), a common plant cultured in China, Korea, Japan and Europe, has been established to have anti-inflammatory, anti-oxidant, anti-allergic, anti-microbial and anti-viral characteristics (7). PV has been revealed to be rich in bioactive chemicals, including polysaccharides, flavonoids, triterpenes and phenolic acid (8). In China, this plant has a history of over a thousand years (9) as a traditional Chinese medicine for use in treating sore throat, swelling of the thyroid gland, jaundice, fever, infectious hepatitis, dermatosis, skin allergies and for accelerating wound healing (10). Previous studies identified that PV regulates cellular immunity via activating the nuclear factor-B and mitogen-activated protein kinase (11), exhibiting anti-estrogenic properties (12), inhibiting the gastric cancer cell SGC-7901 growth in vivo (13), inducing the apoptosis related protein of Raji cells (14) and suppressing lung metastasis (15).

A number of published studies have demonstrated that PV may affect the signal transduction, gene expression and proliferation of lung, gastric and lymphatic tumor cells (13-15). However, the function of PV on WDTC has not yet been reported. The present study investigated the effect of PV on WDTC cell lines (TPC-1 and FTC-133) and explored the activity of apoptosis-associated signaling pathways. The present results show that PV increases apoptosis in WDTC cells in vivo. 


\section{Materials and methods}

$P V$ preparation. PV was provided by Guiyang Xintian Pharmaceutical Co., Ltd. (lot number JG141002; Guizhou, China) and was stored at $4^{\circ} \mathrm{C}$ in the dark. The cell culture medium contained PV at varying concentrations [5, 10, 20 and 30\% (v/v)] was diluted with RPMI-1,640 medium supplemented with $10 \%$ fetal bovine serum (FBS).

Cell lines and cell culture. The human thyroid papillary cancer cell line (TPC-1) and follicular thyroid cancer cell line (FTC-133) were kindly provided by Dr Ye Lei of Shanghai Rui Jin Hospital (Shanghai, China). The cells were cultured in RPMI-1,640 medium supplemented with 10\% FBS in at atmosphere containing $5 \% \mathrm{CO}_{2}$ at $37^{\circ} \mathrm{C}$. The cells were digested by $0.25 \%$ trypsin- $0.01 \%$ EDTA.

Cell Counting Kit-8 (CCK-8) assay. The effect of PV on TPC-1 and FTC-133 cells was measured by the CCK- 8 assay (Dojindo Molecular Technologies, Inc., Kumamoto, Japan). TPC-1 and FTC-133 were seeded at a density of $3 \times 10^{4}$ cells $/ \mathrm{ml}$ in 96-well plates with $100 \mu \mathrm{l}$ per well at $37^{\circ} \mathrm{C}$ for $24 \mathrm{~h}$. Cells were then cultured with different concentrations of PV $[0,5$, $10,20$ and $30 \%(\mathrm{v} / \mathrm{v})]$ for a number of time periods $(12,24$ and $36 \mathrm{~h}$ ). Subsequently, $10 \mu \mathrm{l}$ of CCK- 8 reagent was added to each well, and the 96 -well plates were incubated at $37^{\circ} \mathrm{C}$ for $2 \mathrm{~h}$. The absorbance of each well was determined at $450 \mathrm{~nm}$, using an automatic enzyme-linked immunosorbent assay plate reader (Bio-Rad Laboratories, Inc., Hercules, CA, USA). The relative cell viability was calculated as follows: Cell viability $(\%)=[$ mean optical density $(\mathrm{OD})$ of experimental group/mean OD of control group]x100. Experiments were performed in triplicate. From the values obtained, the half-maximal inhibitory concentration $\left(\mathrm{IC}_{50}\right)$ for the respective durations of treatment was deduced for TPC-1 and FTC-133 cells, using curves obtained by plotting percentage inhibition against concentration.

Hoechst 33342 staining. TPC-1 and FTC-133 cells in the logarithmic growth phase were seeded onto 24 -well plates. Following pre-incubation at $37^{\circ} \mathrm{C}$ for $24 \mathrm{~h}$, cells were treated with PV at $\mathrm{IC}_{50}$. Following $24 \mathrm{~h}$, cells were washed twice with PBS and fixed with $500 \mu 1$ of $4 \%$ paraformaldehyde, at $4^{\circ} \mathrm{C}$ for $10 \mathrm{~min}$. The plate was then washed with PBS and the cells were stained with Hoechst 33342 (Dingguo, Beijing, China) for $5 \mathrm{~min}$ at room temperature in the dark. Subsequently, the cells were washed twice with PBS and immediately observed under an inverted fluorescence microscope (Shenzhen Coosway Optical Technology Co., Ltd., Shenzhen, China) at magnification, $\mathrm{x} 200$. Live cells exhibited dispersion and uniform fluorescence in nuclei, while dead cells were not dyed by Hoechst 33342 staining. When apoptosis occurs, marked nuclear morphological changes may be observed in the nucleus or cytoplasm, including blue fluorescent-stained compact particulates. The cells with three or more fluorescent DNA fragments were identified as apoptotic cells.

Acridine orange (AO)/ethidium bromide (EB) staining. TPC-1 and FTC-133 cells were seeded onto 24 -well plates, then incubated at $37^{\circ} \mathrm{C}$ for $24 \mathrm{~h}$ to allow cell adherence. Following incubation, TPC-1 and FTC-133 cells were treated with PV at $\mathrm{IC}_{50}$, and the treated and untreated cells were washed twice with PBS. A total of $200 \mu \mathrm{l}$ AO/EB (Dingguo) dye mix $(100 \mu \mathrm{g} / \mathrm{ml} \mathrm{AO}$ and $100 \mu \mathrm{g} / \mathrm{ml} \mathrm{EB})$ was added to each well for $3 \mathrm{~min}$. The viability of the cells was examined using fluorescent microscopy (Shenzhen Coosway Optical Technology Co., Ltd.) with 5 separate fields of view at a magnification of $x 200$ to discriminate between live, apoptotic and necrotic cells. AO (green fluorescence) stained live and dead cells, whereas EB (red fluorescence) stained only the dead cells. Apoptotic cells were identified by condensed and fragmented nuclei. Necrotic cells were detected by uniformly orange stained cell nuclei with EB. All the images were captured with a fluorescent microscope equipped with a digital camera.

DNA extraction and fragmentation assay. TPC-1 and FTC-133 cells were treated with $\mathrm{PV}$ at $\mathrm{IC}_{50}$ at $37^{\circ} \mathrm{C}$ for $24 \mathrm{~h}$. DNA was extracted from treated and untreated cells using Takara Minibest Universal Genomic DNA Extraction kit (Takara Biotechnology Co., Ltd., Dalian, China). The genomic DNA samples were separated in $2 \%$ agarose gel by electrophoresis and the gel was stained with Golden View (Dingguo) and visualized under a UV Trans illuminator (Kodak, Rochester, NY, USA).

Reverse transcription-quantitative polymerase chain reaction (RT-qPCR). The expression of the pro-apoptotic genes Bcl-2 associated X protein (Bax) and caspase- 3 , and the anti-apoptotic gene B-cell lymphoma-2 (Bcl-2) were detected by RT-qPCR. The PTC-1 and FTC-133 cells were collected following treatment with $0 \% \mathrm{PV}$ or $\mathrm{PV}$ at $\mathrm{IC}_{50}$ at $37^{\circ} \mathrm{C}$ for $24 \mathrm{~h}$. Total RNA was isolated from cells by TRIzol, (Beijing Solarbio Science \& Technology Co., Ltd., Beijing, China) according to the manufacturer's protocol. The total RNA was reverse transcribed into cDNA using a PrimeScript RT reagent kit with gDNA Eraser (Perfect Real Time; Takara Biotechnology Co., Ltd.). The resulting cDNA was quantified using a RT-qPCR mRNA SYBR Green detection kit (Takara Biotechnology Co., Ltd.) to analyze the expression of apoptosis-associated genes using gene-specific primers. Each reaction was performed in a total volume of $20 \mu \mathrm{l}(10 \mu \mathrm{l}$ Premix, $0.8 \mu \mathrm{l}$ forward primer, $0.8 \mu 1$ reverse primer, $2 \mu \mathrm{l}$ cDNA $6.4 \mu 1 \mathrm{dH}_{2} \mathrm{O}$ ), using SYBR Green PCR reagents (Takara Biotechnology Co., Ltd.) and incubated for $5 \mathrm{sec}$ at $95^{\circ} \mathrm{C}$, followed by 50 cycles of $95^{\circ} \mathrm{C}$ for $5 \mathrm{sec}, 1 \mathrm{cycle}$ of $60^{\circ} \mathrm{C}$ for $20 \mathrm{sec}$ and $60^{\circ} \mathrm{C}$ for $30 \mathrm{sec}$. GAPDH was used as an internal control. The primer sequences were designed using the program primer BLAST as follows: GAPDH forward, 5'-TGAAGGTCGGAGTCAACGG-3' and reverse, 5'-CTGGAAGATGGTGATGGGATT-3'; Bcl-2 forward, 5'-GGGTGGGAGGGAGGAAGAAT-3' and reverse, 5'-TTCGCAGAGGCATCACATCG-3'; Bax forward, 5'-CTC ACCGCCTCACTCACCAT-3' and reverse, 5'-TGTGTCCCG AAGGAGGTTTATT-3'; and caspase-3 forward, 5'-GAGTAG ATGGTTTGAGCCTGAG-3' and reverse, 5'-TGCCTCACC ACCTTTAGAAC-3'. Following PCR, the threshold cycle (Cq) value of each cell was recorded, and the dates were analyzed by the comparative $2^{-\Delta \Delta \mathrm{Cq}}$ method (15).

Statistical analysis. The results are expressed as the mean \pm standard deviation of at least three 
independent experiments. Comparison between groups was performed using one-way analysis of variance. Student's t-test was performed to evaluate the significance of differences in the mean value. $\mathrm{P}<0.05$ was considered to indicate a statistically significant difference. The statistical analyses were performed using the SPSS 17.0 software for Windows (SPSS, Inc., Chicago, IL, USA). GraphPad Prism 5 (GraphPad Software, Inc., La Jolla, CA, USA) was used for graphs.

\section{Results}

Effects of PV on cell proliferation and cell morphology. The effect of PV on cell viability was examined by the CCK- 8 assay. In order to investigate the anti-proliferative effect of PV, TPC-1 and FTC-133 cells were cultured in the presence of various concentrations of PV $(0,5,10,20$ and 30\%) for 12, 24 and $36 \mathrm{~h}$. Subsequent to treatment, the cell viability presented marked changes with different concentrations. The CCK-8 assay showed that PV significantly inhibited the proliferation of TPC-1 and FTC-133 cells $(\mathrm{P}<0.05)$, compared with the control condition (untreated cells). As the concentration increased, the cell viability decreased at all time periods (Fig. 1A and B). Following $24 \mathrm{~h}$ treatment, the $\mathrm{IC}_{50}$ values of PV were found to be 16.3 and $12.7 \%$ PV in TPC-1 and FTC-133 cells, respectively (Fig. 1C). These data indicated that PV significantly reduced the viability of WDTC cells in a dose- and time-dependent manner $(\mathrm{P}<0.05)$.

The CCK-8 assay indicated that PV may effectively inhibit cell proliferation, and this result was confirmed by observing cells under bright inverted microscopy. Following incubation with $\mathrm{IC}_{50} \mathrm{PV}$ for $24 \mathrm{~h}$, cell morphology became smaller in size and more rounded in shape, compared with the control group, resulting in cells detaching from the surface of the Petri dish. The images captured demonstrated that PV caused an alteration in cellular morphology (Fig. 2).

Hoechst 33342 staining. As shown in Fig. 3, the cell nuclei of TPC-1 and FTC-133 cells dyed with Hoechst 33342 were uniform, round or oval, with uniformity in chromatin distribution with a weak blue color. Following treatment with $\mathrm{IC}_{50}$ PV for $24 \mathrm{~h}$, more cells appeared to possess apoptotic characteristics, with changes of nuclear morphometry, including formation of round cell karyorrhexis particles, chromatin condensation, particle shape distribution, bright blue nuclear pyknosis and lobulated nuclear fragmentation.

AO/EB staining to detect nuclear changes. Microscopic evidence for apoptosis was obtained with AO/EB staining, the fluorescent patterns of which depend on the viability and membrane integrity of the cells. Significant changes in morphology were observed following PV treatment for $24 \mathrm{~h}$ at $\mathrm{IC}_{50}$, whereas such changes were not observed in the control group (Fig. 3). Uniformly green fluorescing nuclei with a highly organized cellular structure indicated normal and viable cells (Fig. 3; control 1 and control 2). Orange to red fluorescing nuclei with highly condensed or fragmented chromatin indicated apoptotic cells (Fig. 3; TPC-1 and FTC-133). The present results revealed the apoptosis inducing ability of PV in TPC-1 and FTC-133 cell lines.
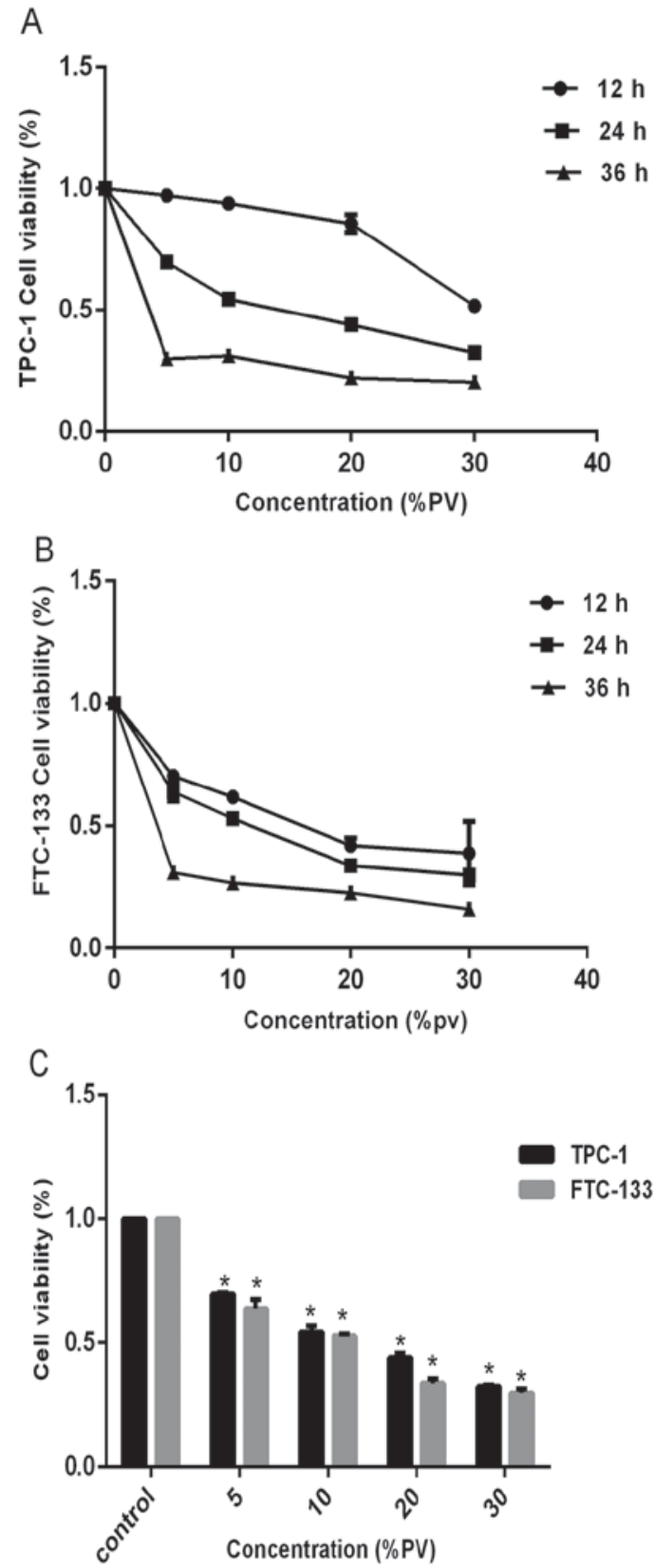

Figure 1. Effects of PV on the proliferation of TPC-1 and FTC-133 by Cell Counting Kit- 8 assay. (A) Dose and time-dependent anti-proliferative effects of PV on TPC-1 cells. (B) Dose and time-dependent anti-proliferative effects of PV on FTC-133 cells. (C) TPC-1 and FTC-133 cells were treated by different concentrations of PV for $24 \mathrm{~h}$. The data are presented as the mean \pm standard deviation for three independent experiments. ${ }^{*} \mathrm{P}<0.05$ compared with the untreated control group. PV, Prunella vulgaris.

DNA fragmentation analysis by $P V$. The effect of PV on cell apoptosis was tested by the DNA ladder formation assay. DNA fragmentation is generally considered to be the hallmark of apoptosis (16). As shown in Fig. 4, DNA laddering was observed subsequent to TPC-1 and FTC-133 cells being treated with $\mathrm{IC}_{50} \mathrm{PV}$ for $24 \mathrm{~h}$, compared with the control groups. The results indicated that PV was able to induce WDTC cell apoptosis.

Effects of PV on the expression of apoptosis-associated proteins. The expression levels of apoptosis-associated 

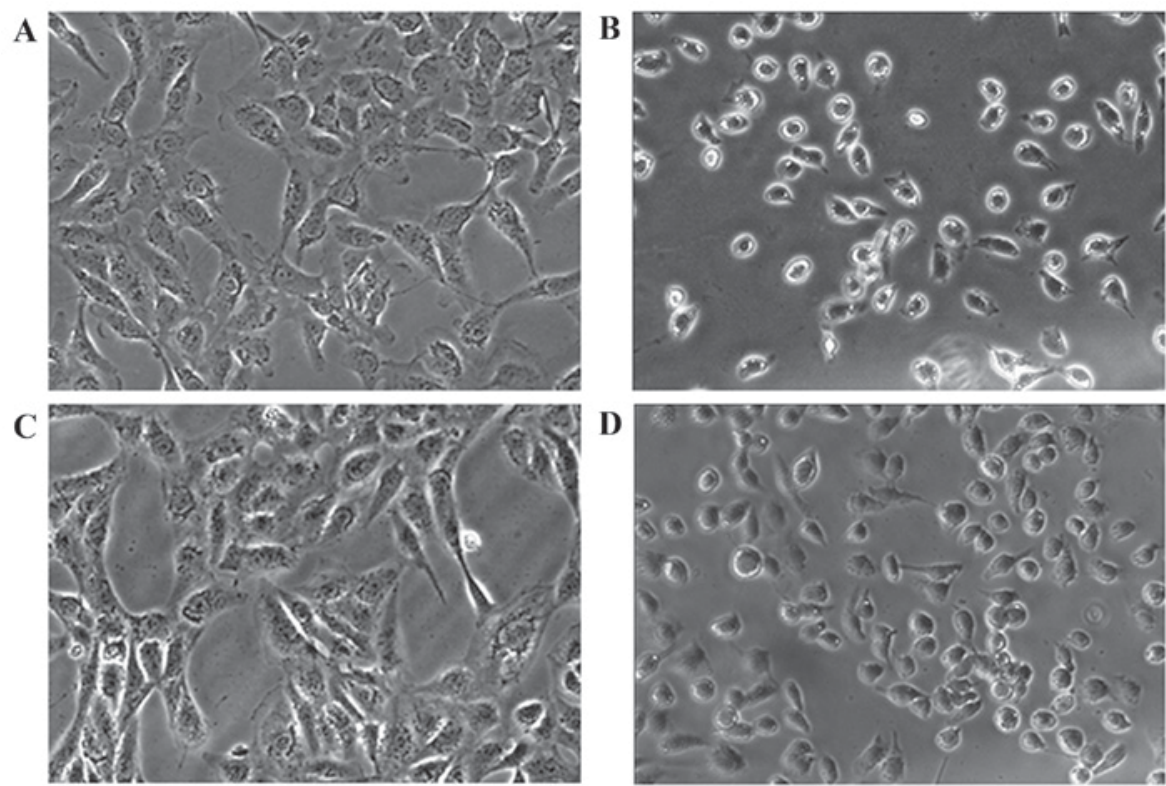

Figure 2. TPC-1 and FTC-133 cell morphological changes following incubation with PV at $\mathrm{IC}_{50}$ for $24 \mathrm{~h}$. (A) TPC-1 untreated group; (B) TPC-1 treated group; (C) FTC-133 untreated group; and (D) FTC-133 treated group. Magnification, $\mathrm{x} 100$. The $\mathrm{IC}_{50}$ value of PV was calculated from cell proliferation plots. Results are the mean \pm standard deviation from three independent experiments. PV, Prunella vulgaris; $\mathrm{IC}_{50}$, half maximal inhibitory concentration.
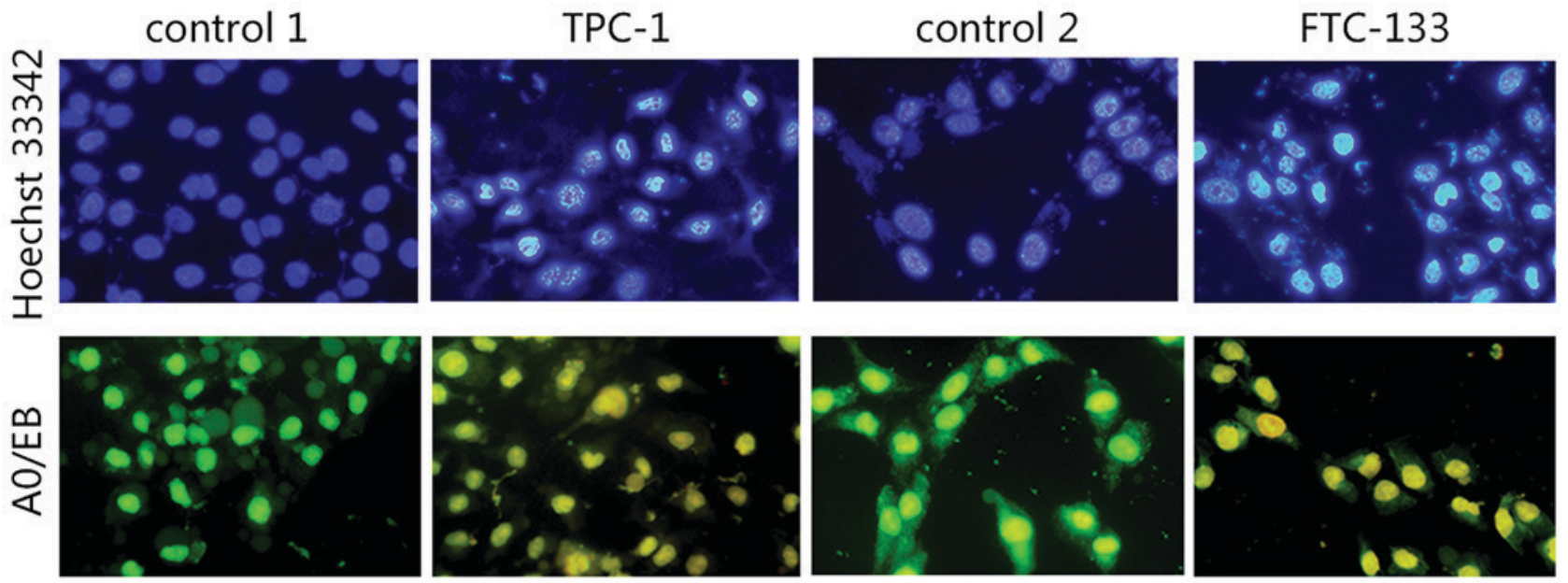

Figure 3. Morphology of cell nuclei in TPC-1 and FTC-133 cells treated with PV, observed by Hoechst 33342 and AO/EB staining. Control 1, TPC-1 untreated group; TPC-1, TPC-1treated group; control 2, FTC-133 untreated group; and FTC-133, FTC-133 treated group. AO/EB, acridine orange/ethidium bromide; PV, Prunella vulgaris.

proteins were assessed by RT-qPCR. The present results showed that the expression level of Bcl-2 was significantly decreased $(\mathrm{P}<0.05)$, while the levels of Bax and caspases-3 increased in TPC-1 and FTC-133 cell lines treated with PV at $\mathrm{IC}_{50}$ for $24 \mathrm{~h}$ (Fig. 5). Previous results demonstrated that the $\mathrm{Bcl}-2$ protein family and the caspase cascade perform key roles in mitochondria-mediated cell apoptosis (17), and the present findings indicated that PV activates Bcl-2, Bax and caspase-3 apoptosis signaling pathways in WDTC TPC-1 and FTC-133 cell lines that were treated with PV.

\section{Discussion}

Due to the advantages of limited side effects and low toxicity of traditional Chinese medicines, there has been increasing attention on the antitumor active ingredients extracted from these medicines (18). PV is a traditional Chinese medicine that has been shown to have potential anti-inflammatory, anti-proliferative and apoptotic effects on diverse cell systems (19). However, the function of PV on WDTC has not been reported.

In order to explore the effect of PV on WDTC cell lines, the present study investigated the anti-proliferative activity of TPC-1 and FTC-133 cell lines following PV treatment. PV showed anti-proliferative effects against TPC-1 and FTC-133 cell lines. The CCK-8 assay showed concentration and time-dependent cytotoxicity of PV. The morphological changes in TPC-1 and FTC-133 cells incubated for $24 \mathrm{~h}$ with $\mathrm{IC}_{50}$ included clumping of cells with round morphology, retraction and shrinking of cells. The present results demonstrated that PV has anti-proliferative potential, which may be useful 


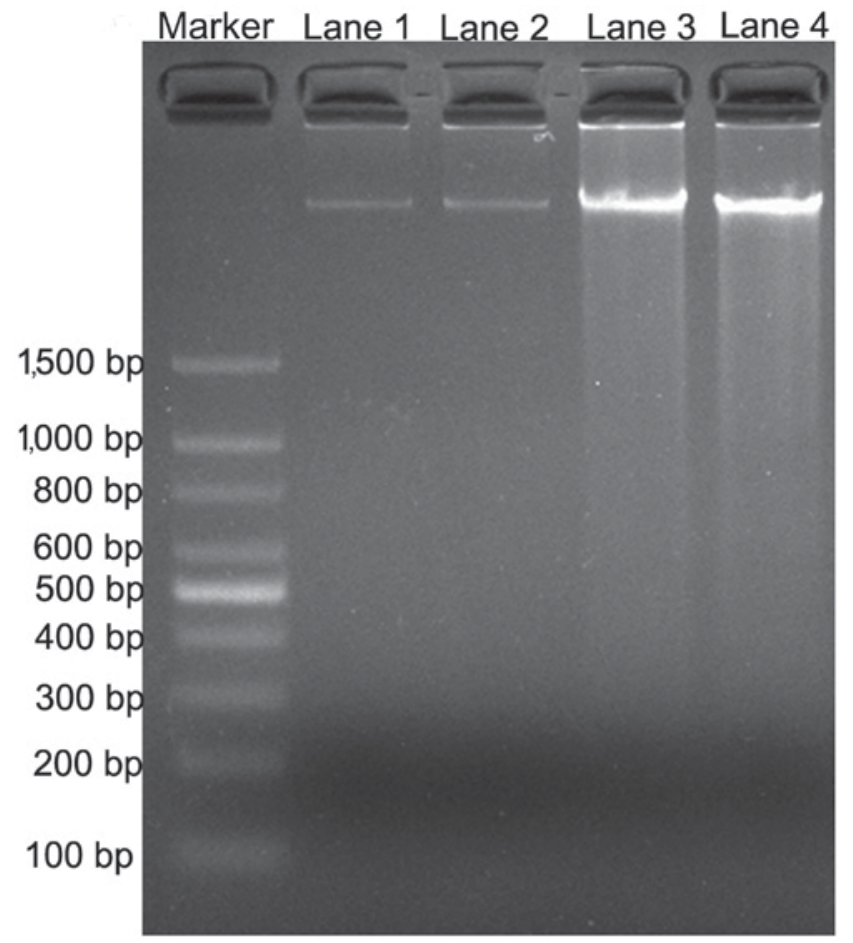

Figure 4. $2 \%$ agarose gel showing DNA fragmentation induced by PV. Marker, 100 bp DNA ladder marker. Lane 1, TPC-1 control group; lane 2, FTC-133 control group; lane 3, TPC-1 treated group; and lane 4, FTC-133 treated group. PV, Prunella vulgaris.

in deriving the novel anticancer drug for WDTC in the future. Fragmented and condensed nuclei in cells are a hallmark of apoptotic induction (20). The cell death pathway that is preferential is apoptosis, although necrosis may also occurred to a certain extent, and these inferences have been substantiated using AO/EB fluorescent staining and Hoechst staining $(20,21)$ The present study showed that the nuclei morphology of papillary thyroid cancer cells was changed significantly following $\mathrm{IC}_{50} \mathrm{PV}$ treatment at $37^{\circ} \mathrm{C}$ for $24 \mathrm{~h}$ (Fig. 3). The present results revealed that $\mathrm{PV}$ inhibited the proliferation of WDTC cell lines by an apoptotic process. DNA fragmentation is generally considered to be the hallmark of apoptosis (22). The present DNA fragmentation data supports earlier observation that PV induced the DNA fragmentation and subsequent cellular damage (Fig. 4).

Mitochondria are cellular organelles, associated with execution of apoptosis (23). This is achieved by regulating the expression of the anti-apoptotic protein $\mathrm{Bcl}-2$ and the pro-apoptotic protein Bax (24). Bcl-2 and Bax come from the Bcl-2 family, which may induce apoptosis by inhibiting oxygen free radicals, controlling intracellular $\mathrm{Ca}^{2+}$ influx, preventing the release of cytochrome $c$ and inhibiting p53 and c-myc (25). The present study also demonstrated that the caspase family of cysteine aspartic proteases performs a role at the start and finish of cell apoptosis, and the caspase- 3 cascade is the key point (26). In order to explore the molecular mechanism underlying PV-induced cell apoptosis, the expression of Bax, caspase-3 and Bcl-2 was detected by RT-qPCR.

The results showed that the mRNA levels of Bcl-2, Bax and caspase- 3 were changed following PV treatment, compared with the control group (Fig. 5). It was also revealed that PV
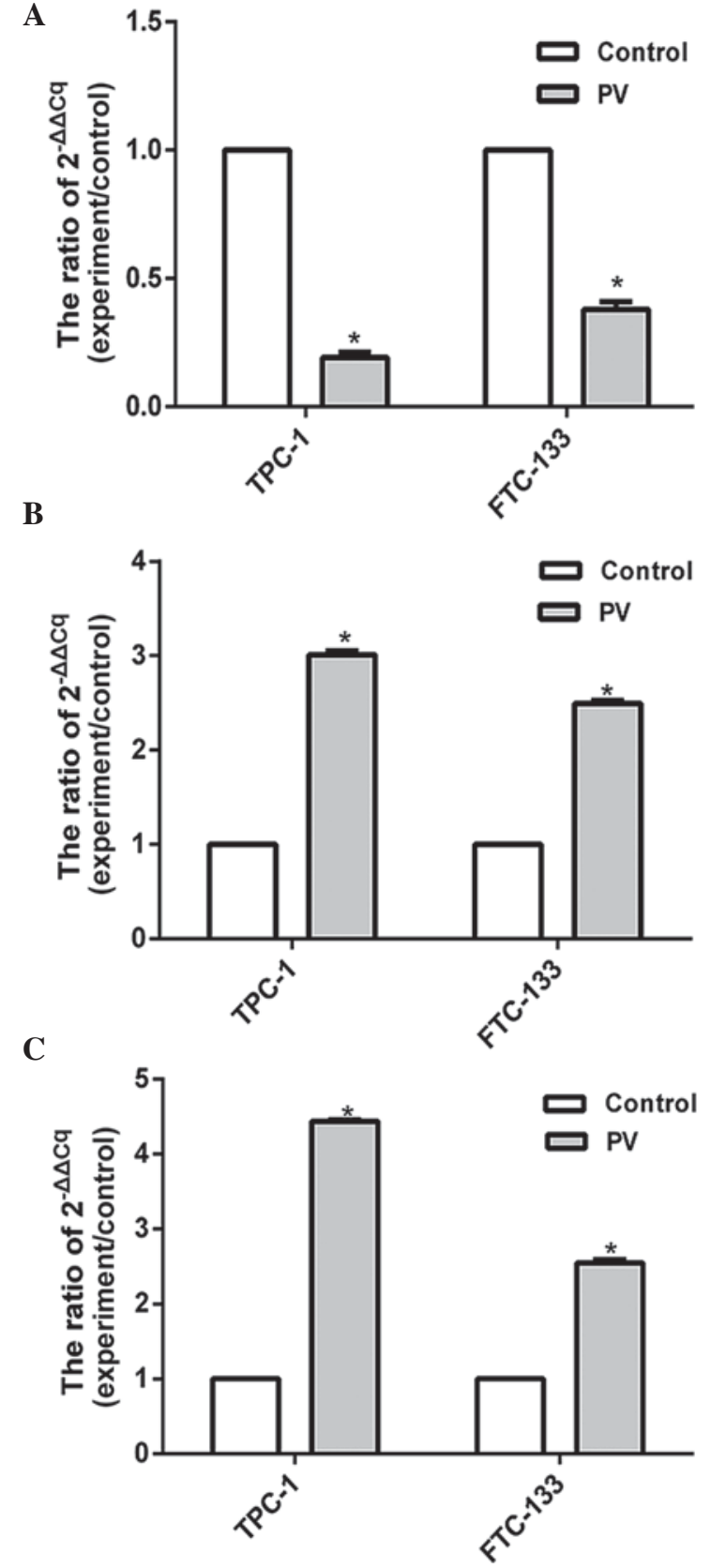

Figure 5. Effects of PV on the expression of Bcl-2, Bax and caspase-3 mRNA in TPC-1 and FTC-133 cell lines. (A) The mRNA level of Bcl-2 was decreased in TPC-1 and FTC-133 cell lines following treatment with PV at $\mathrm{IC}_{50}$ at $37^{\circ} \mathrm{C}$ for $24 \mathrm{~h}$. (B) The mRNA level of Bax was increased in TPC-1 and FTC-133 cell lines following treatment with $\mathrm{PV}$ at $\mathrm{IC}_{50}$ for $24 \mathrm{~h}$. (C) The mRNA level of caspase-3 was upregulated in TPC-1 and FTC-133 cell lines following treatment with $\mathrm{PV}$ at $\mathrm{IC}_{50}$ for $24 \mathrm{~h}$. Each bar represents mean \pm standard deviation of three independent experiments. ${ }^{*} \mathrm{P}<0.05$ vs. control group. B-cell lymphoma-2; Bax, Bcl-2 associated X protein; $\mathrm{PV}$, Prunella vulgaris; $\mathrm{IC}_{50}$, Half-maximal inhibitory concentration.

may improve the level of the pro-apoptotic protein Bax and downregulate the anti-apoptotic protein $\mathrm{Bcl}-2$ expression, activating the caspase- 3 cascade and inducing apoptosis. This may be one of the molecular mechanisms through which PV induces apoptosis on WDTC.

In summary, the present study demonstrated that PV may induce apoptosis in WDTC TPC-1 and FTC-133 cell lines, which was associated with the Bcl-2, Bax and caspase-3 signaling pathways. 


\section{Acknowledgements}

The present study was supported by a grant from the National Natural Science Foundation of China (grant no. 81372863) and the Innovation Scientists and Technicians Troop Construction Projects of Zhengzhou City (grant no. 131PLJRC676).

\section{References}

1. Yin D, Wu W, Li M, Wang QE, Li H, Wang Y, Tang Y and Xing M: DKK3 is a potential tumor suppressor gene in papillary thyroid carcinoma. Endocr Relat Cancer 20: 507-514, 2013.

2. Pacini F, Castagna MG, Brilli L and Pentheroudakis G; ESMO Guidelines Working Group: Thyroid cancer: ESMO clinical practice guidelines for diagnosis, treatment and follow-up. Ann Oncol 23 (Suppl 7): vii110-vii119, 2012.

3. Soares P, Lima J, Preto A, Castro P, Vinagre J, Celestino R, Couto JP, Prazeres H, Eloy C, Máximo V and Sobrinho-Simões M: Genetic alterations in poorly differentiated and undifferentiated thyroid carcinomas. Curr Genomics 12: 609-617, 2011.

4. Gruber JJ and Colevas AD: Differentiated thyroid cancer: Focus on emerging treatments for radioactive iodine-refractory patients. Oncologist 20: 113-126, 2015.

5. Kartal K, Onder S, Kosemehmetoglu K, Kilickap S, Tezel YG and Kaynaroglu V: Methylation status of TSHr in well-differentiated thyroid cancer by using cytologic material. BMC Cancer 15: 824, 2015.

6. Gunda V, Bucur O, Varnau J, Vanden Borre P, Bernasconi MJ, Khosravi-Far R and Parangi S: Blocks to thyroid cancer cell apoptosis can be overcome by inhibition of the MAPK and PI3K/AKT pathways. Cell Death Dis 5: e1104, 2014.

7. Li C, Huang Q, Fu X, Yue XJ, Liu RH and You LJ: Characterization, antioxidant and immunomodulatory activities of polysaccharides from Prunella vulgaris Linn. Int J Biol Macromol 75: 298-305, 2015.

8. Gu X, Li Y, Mu J and Zhang Y: Chemical constituents of Prunella vulgaris. J Environ Sci (China) 25 (Suppl 1): S161-S163, 2013.

9. Guo Q and Chen Y: Textual research on original plant and dietotherapy history of Prunella vulgaris. Zhongguo Zhong Yao Za Zhi 36: 3057-3062, 2011 (In Chinese).

10. Hwang YJ, Lee EJ, Kim HR and Hwang KA: NF-кB-targeted anti-inflammatory activity of Prunella vulgaris var. lilacina in macrophages RAW 264.7. Int J Mol Sci 14: 21489-21503, 2013.

11. Choi JH, Han EH, Hwang YP, Choi JM, Choi CY, Chung YC, Seo JK and Jeong HG: Suppression of PMA-induced tumor cell invasion and metastasis by aqueous extract isolated from Prunella vulgaris via the inhibition of NF-kappaB-dependent MMP-9 expression. Food Chem Toxicol 48: 564-571, 2010.

12. Collins NH, Lessey EC, DuSell CD, McDonnell DP, Fowler L, Palomino WA, Illera MJ, Yu X, Mo B, Houwing AM and Lessey BA: Characterization of antiestrogenic activity of the Chinese herb, prunella vulgaris, using in vitro and in vivo (Mouse Xenograft) models. Biol Reprod 80: 375-383, 2009.
13. Zhao AG, Li T, You SF, Zhao HL, Gu Y, Tang LD and Yang JK: Effects of Wei Chang An on expression of multiple genes in human gastric cancer grafted onto nude mice. World J Gastroenterol 14: 693-700, 2008

14. Zhang KJ, Zhang MZ, Wang QD and Liu WL: The experimental research about the effect of Prunella vulgaris L. on Raji cells growth and expression of apoptosis related protein. Zhong Yao Cai 29: 1207-1210, 2006 (In Chinese).

15. Feng L, Jia X, Zhu M, Chen Y and Shi F: Chemoprevention by Prunella vulgaris L. extract of non-small cell lung cancer via promoting apoptosis and regulating the cell cycle. Asian Pac J Cancer Prev 11: 1355-1358, 2010.

16. Vethakanraj HS, Babu TA, Sudarsanan GB, Duraisamy PK and Ashok Kumar S: Targeting ceramide metabolic pathway induces apoptosis in human breast cancer cell lines. Biochem Biophys Res Commun 464: 833-839, 2015.

17. Leibowitz B and Yu J: Mitochondrial signaling in cell death via the Bcl-2 family. Cancer Biol Ther 9: 417-422, 2010.

18. Hwang SM, Lee YJ, Lee YP, Yoon JJ, Lee SM, Cha JD, Choi KM, Kang DG and Lee HS: Anti-proliferative effect of an aqueous extract of Prunella vulgaris in vascular smooth muscle cells. Evid Based Complement Alternat Med 2013: 936463, 2013.

19. Kim HI, Quan FS, Kim JE, Lee NR, Kim HJ, Jo SJ, Lee CM, Jang DS and Inn KS: Inhibition of estrogen signaling through depletion of estrogen receptor alpha by ursolic acid and betulinic acid from Prunella vulgaris var. lilacina. Biochem Biophys Res Commun 451: 282-287, 2014.

20. Dhivya R, Jaividhya P, Riyasdeen A, Palaniandavar M, Mathan G and Akbarsha MA: In vitro antiproliferative and apoptosis-inducing properties of a mononuclear copper (II) complex with dppz ligand, in two genotypically different breast cancer cell lines. Biometals 28: 929-943, 2015.

21. Schmid I, Uittenbogaart C and Jamieson BD: Live-cell assay for detection of apoptosis by dual-laser flow cytometry using Hoechst 33342 and 7-amino-actinomycin D. Nat Protoc 2: 187-190, 2007.

22. Ahamad MS, Siddiqui S, Jafri A, Ahmad S, Afzal M and Arshad M: Induction of apoptosis and antiproliferative activity of naringenin in human epidermoid carcinoma cell through ROS generation and cell cycle arrest. PLos One 9: e110003, 2014.

23. Zhou WJ, Wang S, Hu Z, Zhou ZY and Song CJ: Angelica sinensis polysaccharides promotes apoptosis in human breast cancer cells via CREB-regulated caspase-3 activation. Biochem Biophys Res Commun 467: 562-569, 2015.

24. Hwang KT, Woo JW, Shin HC, Kim HS, Ahn SK, Moon HG, Han W, Park IA and Noh DY: Prognostic influence of BCL2 expression in breast cancer. Int J Cancer 131: E1109-E1119, 2012.

25. Adams JM and Cory S: Bcl-2-regulated apoptosis: Mechanism and therapeutic potential. Curr Opin Immunol 19: 488-496, 2007.

26. Sabine VS, Faratian D, Kirkegaard-Clausen T and Bartlett JM: Validation of activated caspase-3 antibody staining as a marker of apoptosis in breast cancer. Histopathology 60: 369-371, 2012. 